Original Article

\title{
ASSESSM ENT OF OROPHARYNGEAL WIDTHS IN INDIVIDUALS WITH DIFFERENT FACIAL SKELETAL PATTERNS
}

\author{
Swathi Gupta ${ }^{1} \&$ Ravi M. Subrahmanya ${ }^{2}$ \\ ${ }^{1}$ Consultant Orthodontist, Verma Dental Clinic, Juna Peetha M ain Road, Indore - 452 002, M P. \\ ${ }^{2}$ Professor, Department of Orthodontics, A.B. Shetty Memorial Institute of Dental Sciences, Nitte University, \\ Deralakatte, Mangalore - 575 018, Karnataka, India.
}

Correspondence:

Ravi M. Subrahmanya

Professor, Department of Orthodontics, A.B. Shetty Memorial institute of Dental Sciences Nitte University, Mangalore - 575 018, Karnataka, India.

Mobile : +91 9845221386 E-mail : drmsravi@gmail.com

\section{Abstract:}

Background and objectives: The relationship between airway patency and craniofacial development is highly debated and controversial subject. Hence this was conducted with the aims and objectives of comparing and correlating the upper \& lower Oropharyngeal widths in individuals with horizontal growth pattern with that of individuals having vertical growth pattern.

Methodology : 60 subjects ( 30 males \& 30 females) in the age group of 16 to 20 years were selected as per inclusion criteria. They were divided into two groups (Group I and Group II) according to their skeletal pattern in vertical plane based on Jarabak' sratio and Y axis. Pharyngeal width measurement was done based on M cNamara analysis The data obtained was statistically evaluated using MannWhitneyU test (Ztest).

Results : Significant correlation was found between facial skeletal patterns and upper and lower Oropharyngeal widths. The subjects with vertical skeletal pattern were found to have significantly narrower upper airways and broader lower airways than those with horizontal skeletal pattern.

Interpretation and conclusion : The study supports the existence of a relationship between facial skeletal patterns and upper and lower oropharyngeal widths.

Keywords: Horizontal skeletal pattern; Pharyngeal width; Vertical skeletal patterns.

\section{Introduction:}

The pharynx is a tube-shaped structure formed by muscles and membranes. It is located behind the nasal and oral cavities and the larynx, and extends from the cranial base to the level of the sixth cervical vertebra and the lower border of the cricoid cartilage. Its length is approximately 12 to $14 \mathrm{~cm}$, and it is divided into three parts: nasopharynx, oropharynx, and laryngopharynx. ${ }^{1}$

The nasopharynx and the oropharynx have significant

\begin{tabular}{|c|}
\hline Access this article online \\
\hline Quick Response Code \\
\hline
\end{tabular}
locations and functions because both of them form a part of the unit in which respiration and deglutition are carried out. ${ }^{1}$

A significant relationship exists between the pharynx and dentofacial and skeletal structures. The oropharyngeal airway has been claimed to affect the growth of craniofacial structures. ${ }^{2}$

Nasal obstruction secondary to hypertrophied inferior turbinates, adenoidal pad hypertrophy, and hypertrophy of the faucial tonsils can cause chronic mouth breathing, loud snoring, obstructive sleep apnea, excessive daytime sleepiness, and even corpulmonale. In this situation, a number of postural changes, such as open mandible posture, downward and forward positioning of the tongue, and extension of the head, can take place. ${ }^{1}$

Some authors associated mouth breathing and Class II malocclusion, and others reported associations of vertical growth pattern with obstruction of upper and lower pharyngeal airways concurrently with mouth breathing. If this relationship actually exists, Class I malocclusions and 
vertical growth patterns must have natural anatomic predisposition factors. Among the predisposing factors for obstruction of the pharyngeal airways such as allergies, environmental irritants, and infections, which are amenable to adequate treatment, there is also the natural anatomic predisposition of narrower airway passages. ${ }^{3}$

Consequently healthy patients with Class II malocclusions and vertical growth patterns might have narrower airway passages than healthy patients with normal malocclusions and growth patterns, or Class I malocclusion. ${ }^{4}$

Hence this study is designed and planned to measure the upper and lower pharyngeal airway dimensions in children with different skeletal patterns in vertical plane.

\section{Materials and Method:}

60 individuals (30 males $\& 30$ females) in the age group of 16 to 20 years were selected as per the following criteria for subjects with different vertical growth patterns.

\section{Inclusion criteria:}

I Individuals in the age group of 16 to 20 years.

I Clinically obvious long and short faced individuals.

I Individuals with full complement of teeth up to $2^{\text {nd }}$ Molar.

I Individuals willing to participate in the study.

\section{Exclusion criteria:}

I Presence of any pharyngeal pathology.

I Individuals with enlarged tonsils and patients with history of repeated common cold.

I Individuals with complaints of nasal obstruction.

I Any craniofacial syndromes/medically unfit.

I Patients with abnormal habits.

1 Patients with history of previous orthodontic treatment and / or surgical treatment.

The subjects fulfilling the above criteria were requested to participate in the study. After obtaining the informed consent, lateral cephalograms were made for each individual in a standardized technique using the Planmeca PM 2002 cc Proline machine (Planmeca,Finland). The lateral cephalograms were traced on 0.003 inch acetate paper by the same operator in order to avoid interoperatorerrors.

The subjects were divided into two groups according to their skeletal pattern in vertical plane based on Jarabak's ratio (Posterior facial height/Anterior facial height x100) and Y axis (SN-Gn angle). (Table 1)

The following linear measurements were made on lateral cephalogram:

\section{Pharyngeal width measurement based on McNamara analysis ${ }^{4}$ (Figure 4)}

I Upper Oropharyngeal width (UOPW in mm): The upper airway is measured from a point on the posterior outline of the soft palate to closest point on the posterior pharyngeal wall.

Lower Oropharyngeal airway width (LOPW in $\mathrm{mm}$ ): The lower airway is measured from the point of intersection of the posterior border of the tongue and the inferior border of the mandible to the closet point on the posterior pharyngeal wall.

The data obtained was statistically evaluated by using $M$ ann-Whitney $U$ test ( $Z$ test) to test the significance of difference in the upper and lower oro-pharyngeal widths in children with horizontal and vertical skeletal pattern.

\section{Results:}

The present study was undertaken with the intention of evaluating \& comparing the upper and lower pharyngeal airway in subjects with different vertical growth patterns.They were divided into two groups according to their skeletal pattern in vertical plane on the basis of 2 facial parameters; Jarabak's ratioand Yaxis.

The mean and standard deviation of the upper and lower pharyngeal airway widths were measured in Groups I and II. Mann- Whitney $U$ test ( $Z$ test) was applied to test whether there were any differences between the groups for upper and lower pharyngeal widths,

\section{Pharyngeal Measurements:}

Within the groupsno significant differences were observed 
in the mean values of the upper and lower pharyngeal widths in both males and females. (Table 2)

\section{Upper Oropharyngeal width (UOPW)}

The mean value of the UOPW for entire Group I was found to be $13.57 \mathrm{~mm}$ (SD $2.687 \mathrm{~mm}$ ) whereas entire Group II had a mean value of $9.47 \mathrm{~mm}$ (SD $2.403 \mathrm{~mm}$ ).

The differences in the mean values between males in the groups were found to be very highly significant $(p=0.00)$. (Table 3, Graph 1)

The mean value of the UOPW for males in Group I was found to be $13.6667 \mathrm{~mm}$ (SD 2.31969mm) whereas Group II had a mean value of $8.9333 \mathrm{~mm}$ (SD $2.21897 \mathrm{~mm}$ ). The differences in the mean values between the groups were found to be very highly significant $(p<0.001)$. (Table 4 , Graph 2)

The mean value of the UOPW for females in Group I was found to be $13.4667 \mathrm{~mm}$ (SD $3.09069 \mathrm{~mm}$ ) whereas females in Group II had a mean value of 10.0000 mm (SD $2.53546 \mathrm{~mm}$ ). The differences in the mean values between the groups were found to be highly significant $(p=0.004)$. (Table 4, Graph 3)

\section{Lower Oropharyngeal width (LOPW)}

The mean value of the LOPW for entire Group I was found to be $8.93 \mathrm{~mm}$ (SD $2.149 \mathrm{~mm}$ ) whereas entire Group II had a mean value of $10.30 \mathrm{~mm}$ (SD $2.307 \mathrm{~mm}$ ). The differences in the mean values between the groups were found to be significant $(p=.020)$. (Table 3, Graph 1 )

The mean value of the LOPW for males in Group I was found to be $10.3333 \mathrm{~mm}$ (SD $2.82000 \mathrm{~mm}$ ) whereas males in Group II had a mean value of $9.5333 \mathrm{~mm}$ (SD $2.53170 \mathrm{~mm}$ ). The differences in the mean values between the groups were not found to be significant ( $p=0.217$ ). (Table 4 , Graph 2)

The mean value of the LOPW for females in Group I was found to be $9.6667 \mathrm{~mm}$ (SD $2.55417 \mathrm{~mm}$ ) whereas females in Group II had a mean value of $10.8667 \mathrm{~mm}$ (SD1.88478mm). The differences in the mean values between the groups were found to be significant $(p=0.04)$.

(Table 4, Graph 3)

Figure 1: Measurement of pharyngeal airway based on McNamara analysis

$A=$ Upper Pharyngeal Width

$B=$ Lower Pharyngeal Width

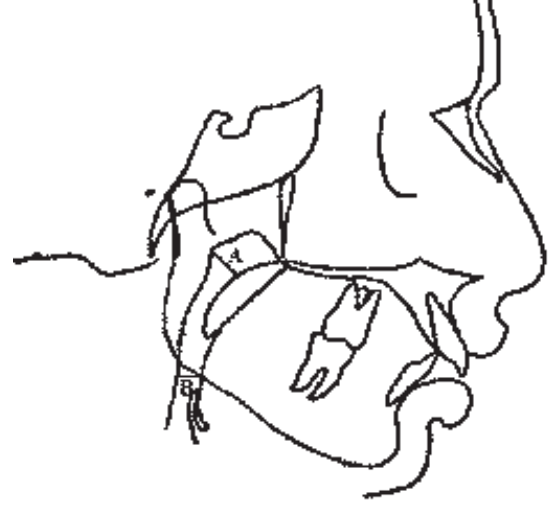

Graph 1: Upper and Lower Oropharyngeal widths in subjects with horizontal and vertical growth patterns

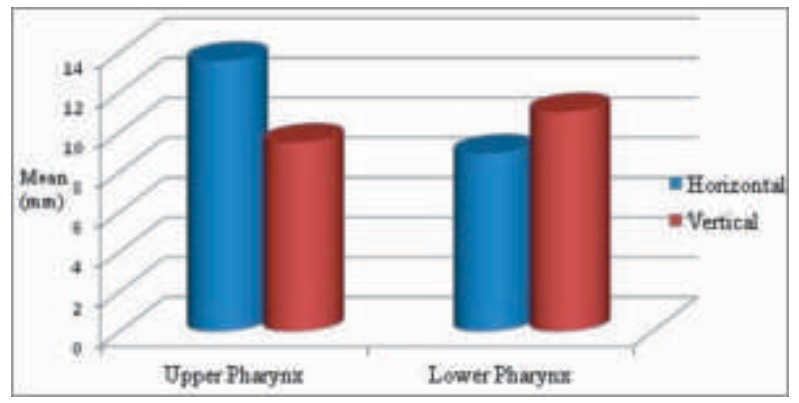

Graph 2: Upper and Lower Oropharyngeal widths in Males with horizontal and vertical growth patterns

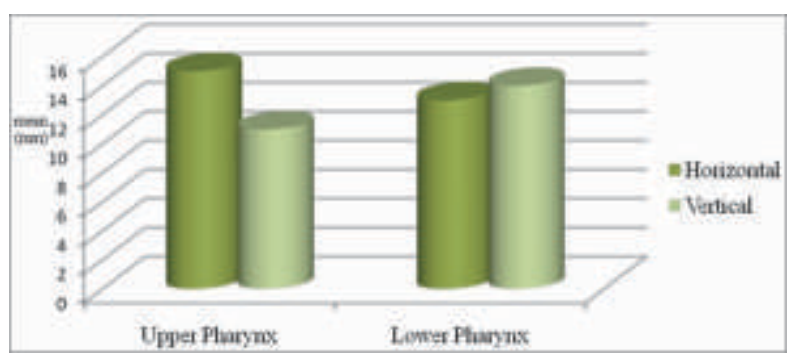

Graph 3: Upper and Lower Oropharyngeal widths in Females with horizontal and vertical growth patterns

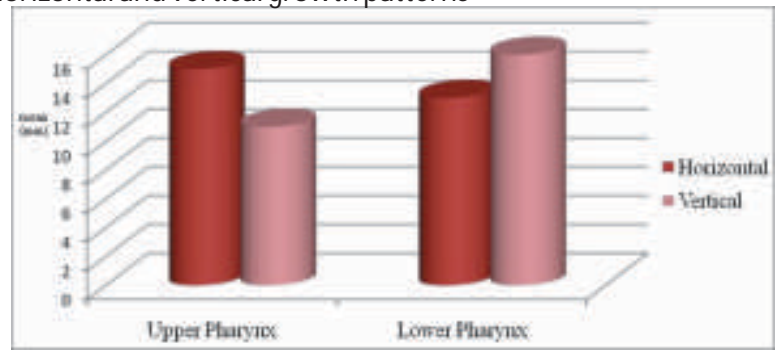


Table 1: Distribution of subjects into groups

\begin{tabular}{|l|c|c|c|c|}
\hline Group & \multicolumn{2}{|c|}{ No. of subjects } & Mean Jarabak's & Mean Y Axis \\
\hline & & & Ratio (\%) & (Degree) \\
\hline Group I & 30 & $15 \mathrm{M}$ & 68.41 & 52.46 \\
& & $15 \mathrm{~F}$ & 66.69 & 51.8 \\
\hline Group II & 30 & $15 \mathrm{M}$ & 56.77 & 66.13 \\
& & $15 \mathrm{~F}$ & 55.75 & 67.13 \\
\hline
\end{tabular}

Table 2: Upper and lower Oropharyngeal widths in males and females within each group

\begin{tabular}{|c|c|c|c|c|c|c|}
\hline $\begin{array}{l}\text { Pharyng- } \\
\text { eal width }\end{array}$ & $\begin{array}{l}\text { Growth } \\
\text { pattern }\end{array}$ & Gender & $\begin{array}{c}\text { No. of } \\
\text { subjects }\end{array}$ & $\begin{array}{l}\text { Mean } \\
(\mathrm{mm})\end{array}$ & $\begin{array}{c}\text { Std. De- } \\
\text { viation }\end{array}$ & p \\
\hline \multirow[t]{4}{*}{ UOPW } & \multirow[t]{2}{*}{ Horizontal } & Male & 15 & 13.6667 & 2.31969 & \multirow[t]{2}{*}{$0.601 \mathrm{~ns}$} \\
\hline & & Female & 15 & 13.4667 & 3.09069 & \\
\hline & \multirow[t]{2}{*}{ Vertical } & Male & 15 & 8.9333 & 2.21897 & \multirow[t]{2}{*}{$0.131 \mathrm{~ns}$} \\
\hline & & Female & 15 & 10.0000 & 2.53546 & \\
\hline \multirow[t]{4}{*}{ LOPW } & \multirow[t]{2}{*}{ Horizontal } & Male & 15 & 8.6667 & 2.22539 & \multirow[t]{2}{*}{$0.449 \mathrm{~ns}$} \\
\hline & & Female & 15 & 9.2000 & 2.11119 & \\
\hline & \multirow[t]{2}{*}{ Vertical } & Male & 15 & 9.7333 & 2.60403 & \multirow[t]{2}{*}{$0.18 \mathrm{~ns}$} \\
\hline & & Female & 15 & 10.8667 & 1.88478 & \\
\hline
\end{tabular}

[ $p \varangle 0.001$ is very highly significant (vhs), $p \ll 0.01$ is highly significant (hs), $p<0.05$ is significant (s), $p>0.05$ is not significant.]

Table 3: Upper and lower Oropharyngeal widths in both the groups

\begin{tabular}{|l|c|c|c|c|c|}
\hline $\begin{array}{l}\text { Pharyngeal } \\
\text { width }\end{array}$ & Group & $\begin{array}{c}\text { No. of } \\
\text { subjects }\end{array}$ & $\begin{array}{c}\text { Mean } \\
\text { (mm) }\end{array}$ & $\begin{array}{c}\text { Std. } \\
\text { Deviation }\end{array}$ & p \\
\hline \multirow{2}{*}{ UOPW } & Group I & 30 & 13.57 & 2.687 & \multirow{2}{*}{000 vhs } \\
\cline { 2 - 5 } & Group II & 30 & 9.47 & 2.403 & \\
\hline \multirow{2}{*}{ LOPW } & Group I & 30 & 8.93 & 2.149 & $.020 \mathrm{~s}$ \\
\cline { 2 - 5 } & Group II & 30 & 10.30 & 2.307 & \\
\hline
\end{tabular}

[ $p<0.001$ is very highly significant (vhs), $p<0.01$ ishighly significant (hs), $p<0.05$ is significant (s), $p>0.05$ is not significant. ]

Table 4: Upper and lower Oropharyngeal widths in males and females in both the groups

\begin{tabular}{|c|c|c|c|c|c|c|}
\hline $\begin{array}{l}\text { Pharynge- } \\
\text { al width }\end{array}$ & Gender & Group & $\begin{array}{l}\text { No. of s } \\
\text { ubjects }\end{array}$ & $\begin{array}{l}\text { Mean } \\
(\mathrm{mm})\end{array}$ & $\begin{array}{l}\text { Std. De- } \\
\text { viation }\end{array}$ & $\mathbf{p}$ \\
\hline \multirow[t]{4}{*}{ UOPW } & \multirow[t]{2}{*}{ Male } & Group & 15 & 13.6667 & 2.31969 & \multirow{2}{*}{$\begin{array}{c}\varangle .001 \\
\text { vhs }\end{array}$} \\
\hline & & Group I & 15 & 8.9333 & 2.21897 & \\
\hline & \multirow[t]{2}{*}{ Female } & Group & 15 & 13.4667 & 3.09069 & \multirow{2}{*}{$\begin{array}{c}0.004 \\
\text { hs }\end{array}$} \\
\hline & & Group I & 15 & 10.0000 & 2.53546 & \\
\hline \multirow[t]{4}{*}{ LOPW } & \multirow[t]{2}{*}{ Male } & Group & 15 & 10.3333 & 2.82000 & \multirow{2}{*}{$\begin{array}{c}0.217 \\
\text { ns }\end{array}$} \\
\hline & & Group I & 15 & 9.5333 & 2.53170 & \\
\hline & \multirow[t]{2}{*}{ Female } & Group & 15 & 9.6667 & 2.55417 & \multirow[t]{2}{*}{$0.04 \mathrm{~s}$} \\
\hline & & Group I & 15 & 10.8667 & 1.88478 & \\
\hline
\end{tabular}

[ $p<0.001$ is very highly significant (vhs), $p<0.01$ is highly significant (hs), $p<0.05$ issignificant (s), $p>0.05$ is not significant. ]

\section{Discussion:}

The cranio facial growth and development is very complex and multifactorial. As clinicians, Orthodontists should consider various factors that contribute to the craniofacial development. The relationship between airway patency and craniofacial development is highly controversial not only having academic implications but also having considerable clinical consequences. It can influence the orthodontist's decision on diagnosis and treatment planning. $^{5}$

Individuals with dolichocephalic growth patterns are reported to have a tendency toward an obtuse cranial base angle. ${ }^{6,7}$ However, few studies reveal that the cranial base in the long face syndrome is essentially normal. ${ }^{8,9}$

According to a study in which a sample of persons with long face syndrome was compared with a group of persons with small face syndrome, the former was found to have smaller nasopharyngeal cavities. ${ }^{10} \quad$ According to a study, subjects with Class I and Class II malocclusions and vertical growth patterns have significantly narrower upper pharyngeal airways than those with Class I and Class II malocclusions and normal growth patterns. Also the malocclusion type does not influence upper pharyngeal width, and malocclusion type and growth pattern do not influence lower pharyngeal width. ${ }^{3}$

The present study measured and compared the upper and lower pharyngeal airway widths in subjects with horizontal and vertical facial skeletal patterns. 30 subjects with horizontal skeletal pattern (15 males, 15 females) and 30 with vertical skeletal pattern (15 males, 15females) were selected as per the established indicators of facial pattern, $Y$ axis ${ }^{11,12}$ and Jarabak's ratio ${ }^{13}$. Pharyngeal measurements were made based on M cNamara analysis ${ }^{4}$.

Significant difference was observed between upper and oropharyngeal widths and facial skeletal pattern. Subjects with vertical skeletal pattern have significantly narrower upper airways than those with horizontal skeletal pattern. This finding is in agreement with those of $\mathrm{M}$ arcos Roberto de Freitas et al who had conducted a similar study earlier. ${ }^{3}$ This finding is further supported by a study according to which higher and shallower pharyngeal dimension were found in individuals with dolichocephalic growth pattern. ${ }^{5}$ 
According to the present study, the Subjects with vertical skeletal pattern have significantly broader lower airways than those with horizontal skeletal pattern. This finding is not in agreement with a study by Marcos Roberto et al, according to which growth patterns do not influence lower pharyngeal airway width. ${ }^{3}$ According to a study by Peter et al, Long faced subjects were found to have higher mean value of nasal resistance. ${ }^{14}$

The findings generated from the present study partly support the hypothesis that upper pharyngeal airway width is narrower in long faces in comparison to short faces. The cause of such variation can only be speculated upon and a definite cause and effect relationship is yet to be demonstrated.

The findings of this study have certain clinical implications.

The study has shown a significant correlation between upper and lower Oropharyngeal widths and facial skeletal pattern. This fact should be considered during diagnosis

\section{References}

1. Ismail Ceylan, Husamettin Oktay .A study on the pharyngeal size in different skeletal patterns. Am J OrthodDentofacOrthop 1995(108):69-75.

2. Elham Saleh Abu Allhaija, Susan Nandeem Al-Khateeb.Uvulo-Glossopharyngeal dimensions in different antero-posterior skeletal patterns. Angle Orthod 2005:75:1-13.

3. Marcos Roberto de Freitas, Nandyr Maria Penteado, Virmond Alcazar. Upper and lower pharyngeal airways in subject with Class I and Class II malocclusions and different growth patterns. Am J Orthod Dentofacial Orthop 2006; 130:742-45.

4. M cNamara JA. A method of cephalometric evaluation. Am J Orthod Dentofacial Orthop 1984; 86(6):449-469.

5. Luc P.m.Tourne. Growth of the pharynx and its physiologic implications. Am J Orthod DentofacialOrthop 1991(129-139):1-24.

6. Enlow DH. Handbook of facial growth. Philadelphia:WB Saunders 1975;56-57.

7. SassouniV, A classification of facial types.AM J Orthod 1969;55:109

8. Ellis $E$, McNamara JA. Components of adult class III open bite malocclusion. AM J Orthod 1984;86:277

9. Issacson JR, Speidel MT, Worms WF. Extreme variations in vertical growth and associated variations in skeletal and dental relations. Angle Orthod 1971;41:219-29.

10. Kerr WJ. The nasopharynx, face height and overbite. Angle Orthod,1985;55:31-6.

11. Downs WB. Analysis of the dentofacial profile. Angle Orthod 1956; 26:192-212.

12. Downs WB. The role of cephalometry in orthodontic case analysis and diagnosis. Am J OrthodDentofacialOrthop1952;38:162-82.

13. M ayury, M aria Beatriz de Araujo. Jarabak's Cephalometric Analysis of Brazilian Black Patients. BrazDent J 2007: 18(3).

14. Peter S. Vig, David M. Sarver, David J. Hall, Donald W. Warren. Quantitative evaluation of nasal airflow in relation to facial morphology. Am J Orthod DentofacialOrthop 1981; 79(3):263-72 and treatment planning.However, upper and lower Oropharyngeal widths determinethe facial skeletal pattern of an individual or the vice-versa needs to be investigated further. A further study comprising of larger sample size is required so that the actual relation can be established

\section{Conclusions:}

The following conclusions can be drawn from the study:

I Variations are observed in upper and lower oropharyngeal widths and posture of the tongue in subjects with horizontal skeletal pattern and vertical skeletal pattern.

I The upper oropharyngeal width is seen to be narrower in subjects with vertical skeletal pattern.

I The lower oropharyngeal width is seen to be wider in subjects with vertical skeletal pattern.

I A significant co-relation was found between the facial skeletal pattern and the upper and lower oropharyngeal widths. 